\title{
'Patent trolls' target biotechnology firms
}

\section{Opportunistic patent litigation threatens the life sciences.}

\section{BY ERIKA CHECK HAYDEN}

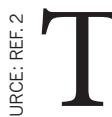

The biotechnology industry has had its share of woes, but so far 'patent trolls' have not numbered among them. These

\& companies, which profit by legally enforcing patents they own rather than developing products, may benefit from a 31 August ruling at a US federal court of appeal in Washington DC.

The court upheld a lawsuit filed by Classen Immunotherapies of Baltimore, Maryland, against four biotechnology companies and a medical group, for infringing on a patent that covered the idea of trying to link infant vaccination with later immune disorders. A district court had thrown out the lawsuit, finding that the concept at the heart of the case amounted to an abstract idea that could not be patented. The appeals court found otherwise.

Beyond its complex particulars, the case sets "a troubling precedent", says James Bessen, a lawyer at the Boston University School of Law, Massachusetts, "because you're patenting something that's very broad". (The patents include the act of reading the published scientific literature and using it to create vaccination schedules that minimize immune disorders.)

Joseph Zito, the plaintiff's lawyer, says that his client, John Barthelow Classen, was the first researcher to connect vaccination schedules to immune disorders through animal studies. "He doesn't want to stop anybody," Zito says. "He wants to make sure people use vaccines safely." But very broad patents have posed a problem in the technology field, where some firms amass vast portfolios of patents bought up from inventors and look for targets to sue.

\section{HARMING SOCIETY}

In a study released on 19 September, Bessen and his co-authors estimate that patent lawsuits filed by trolls, also known as 'non-practicing entities' (NPEs), caused defendants to lose more than US $\$ 500$ billion in value from 1990 to 2010 (ref. 1). The figure was calculated by analysing the effect on defendants' stock prices when they were sued.

"We conclude that the loss of billions of dollars of wealth associated with these lawsuits harms society," the authors write.

In 2009, Colleen Chien, a lawyer and patent expert at Santa Clara University in California, calculated that the proportion of patent-litigation cases involving NPEs grew

\section{COURTING CHAOS}

US patent litigation involving 'non-practicing entities' (NPEs) is rising (dashed line) as is the proportion of defendants in NPE cases (solid line).

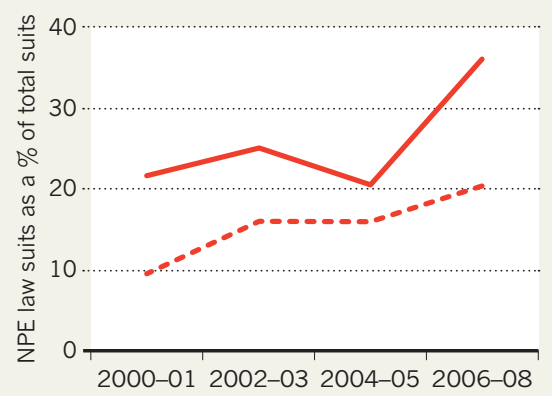

from $10 \%$ to $20 \%$ between 2000 and 2008 . The proportion of defendants whose cases involve NPEs - which is disproportionately high rose from $22 \%$ to $36 \%$ in the same period ${ }^{2}$ (see 'Courting chaos'). Roughly two-thirds of all suits are over software patents, but experts warn that the life sciences are not immune.

"There is definitely reason for concern in the biotech field," says Julie Samuels, a staff attorney at the non-profit Electronic Frontier Foundation in San Francisco, California.

So far, Chien says, biotechnology companies have not been as vulnerable because their patents are not as broad as software patents, and require more time and expertise to develop. Yet the Classen case shows that broad patent claims can survive in court. And some of the largest patent holders are showing signs that they are interested in the biotechnology sector. For example, Intellectual Ventures of Bellevue, Washington, founded by Nathan Myhrvold, a former Microsoft executive, owns hundreds of patents in the biotechnology industry. The company says it has no plans to litigate in the field.

A weak economy could also become a factor if it leads biotech companies to sell off their patents to opportunistic litigators. And if companies start profiting from troll behaviour, the practice will spread, says lawyer Robert CookDeegan of Duke University in Durham, North Carolina. "If people do it and get away with it, it sets up an incentive for other people to behave the same way," he says.

1. Bessen, J. E. et al. Boston Univ. School of Law, Law and Economics Research Paper 11-45 (2011).

2. Chien, C. V. North Carolina Law Review 87, 1571-1615 (2009). 